Review of Income and Wealth

Series 46, Number 3, September 2000

\title{
DOMINANCE TESTING OF TRANSFERS IN ROMANIA
}

\author{
by David E. Sahn, Stephen D. Younger and Kenneth R. Simler \\ Cornell University
}

In this paper we compare the progressivity of different government transfers made to households in Romania. We use distribution free standard errors to examine the difference between concentration curves that may be correlated, and thereafter employ statistical tests that take into account the covariance matrix for the ordinate estimates. In addition, we estimate extended Gini coefficients for the same transfers to check their consistency with the tests of inequality dominance. The results show that almost all transfer payments in Romania are progressive, and that they have an important effect on the distribution of income. Rankings among different transfer payments are, however, not robust. In particular, sensitivity analysis using different household equivalence scales indicates that many results are not consistent across scales, and that lower size elasticities contribute to changes in ranking of Ginis and loss of statistical significance in dominance tests.

\section{INTRODUCTION}

Like many other formerly socialist economies, Romania has been undergoing a transition to a market economy, with significant declines in household incomes and aggregate output. In the years following economic liberalization, 1990 to 1994, unemployment rose, real wages fell, and GDP in all sectors of the economy declined at rates even higher than most of its eastern European neighbors. Despite the hardships endured to date, structural reform has proceeded slowly, leaving the country facing the prospect of even more difficult times ahead.

Romania's generous system of pensions and transfer payments plays a dual role in these reforms. On the one hand, transfers are a large share of government expenditure, about one-third in 1991-2, or 10 percent of GDP, and thus contribute to unsustainable fiscal imbalances that threaten macroeconomic stability. On the other hand, most Romanians believe that these transfers benefit poorer households for whom the burden of the economic collapse is especially onerous. If this is true, policymakers face a trade-off between macroeconomic stability and progressive redistribution of income.

The purpose of this paper is to examine the incidence of public spending on the major pensions and transfer payments in Romania. ${ }^{1}$ That is, we test the extent to which public transfers really are progressive and thus, the extent to which they help poorer households in these difficult times. In addition, comparison of the relative progressivity of different transfer payments should help the government

Note: The authors greatly appreciate the comments and suggestions of Jean-Yves Duclos and two anonymous referees. The authors conducted part of this research while Stephen D. Younger was a visiting Research Fellow at the Free University in Amsterdam. They gratefully acknowledge that University's financial support and hospitality.

${ }^{1}$ In our analysis, we do not account for behavior responses that could affect our results, such as changes in labor supply and inter-household transfers. See, for example, Ravallion, van de Walle, and Gautam (1995). 
target scarce resources to poorer households. Our data come from a 1993-94 survey of households in Romania (Government of Romania, 1994).

Our methods employ several recent advances in the literature on welfare dominance. First, we use the covariance estimator of Davidson and Duclos (1997) to calculate statistical tests for the difference in concentration curves rather than simply comparing ordinates. An attractive feature of this estimator is that it allows the underlying variables to be correlated, which is important for crosssectional comparisons of targeted transfer payments that are correlated with incomes by design. Second, we use a decision criterion that differs from most of the literature for rejection of the null of no dominance. Howes (1996a) shows that a common test, which rejects the null in favor of dominance if the t-statistic for the difference in any ordinate pair is significant, and no other pair is significant with the opposite sign, has an indeterminate size. ${ }^{2}$ Only by rejecting the null if and only if all ordinates differ (in the same direction) can we be sure that the size is bounded. Finally, we recognize that sensible dominance tests must be "restricted" to a range of ordinates away from the extremes of zero and one, since it will be virtually impossible to reject the null of equal ordinates near these extremes in any finite sample. ${ }^{3}$ However, once again we go beyond the standard practice of comparing ordinates at the decile breaks, and consider finer divisions of percentiles.

Our use of more careful testing procedures means that we are able to reject the null in favor of dominance in relatively few cases, particularly compared with the existing literature. For that reason, we also include information on cardinal comparisons between transfer payments, based on extended Gini coefficients. These comparisons are also statistical, using the Davidson and Duclos (1997) results. We find that they often give more conclusive results, even when using a parameterization that strongly favors equality. This difference highlights how demanding a finding of welfare dominance is.

Finally, because many of the transfers that we study are intended to be correlated with family size or composition, we repeat our tests for different assumptions about the proper household equivalence scale. In most cases, the results are not at all robust to these variations, suggesting that the unavoidable yet essentially arbitrary choice of the "correct" household welfare function can have an important effect on policy conclusions.

The remainder of the paper is organized as follows. Section 2 briefly discusses the data and presents descriptive statistics that will aid in interpreting the results that follow; Section 3 discusses methods; and, Section 4 presents the results. We conclude with a discussion of the results' implications for policy in Romania and future research in this field.

\section{Data and Descriptive Statistics}

The data come from the Romania Integrated Household Survey, (Government of Romania, 1994) which interviewed 16,565 households during the period

\footnotetext{
${ }^{2}$ Bishop, Formby, and Thistle (1992) introduced this test.

${ }^{3}$ See Howes $(1996 \mathrm{~b})$ for a discussion of related issues.
} 
April, 1994 to September, 1994. We adjusted the sample to be representative of the Romanian population through the application of household weights. The survey collected detailed information on household incomes, public transfers, labor market activity, and a wide number of living standards indicators.

In Romania, like in other countries in Eastern Europe, public transfers are an important share of household income. Social security pensions are most important among them, both in terms of the share of recipient households and value per recipient household (Table 1). This pay-as-you-go system was designed to protect families primarily in old age, but also due to disability. More than onequarter of the households in Romania receive these payments. About half that number of households receives agriculture pensions, and the payment per household among those receiving agricultural pensions is less than 20 percent of the value of social security pensions.

Child allowances represents another important entitlement, which in contrast to pensions, is universal and not linked with payment into the scheme. Over 40 percent of the households receive child allowances, although their monthly value is small compared with social security payments. These monthly allowances for children under 16 decrease slightly by family income, but increase by number of children. A premium is also provided for handicapped children, in addition to their being eligible for benefits up to age 18 .

Unemployment benefits are provided for nine months after losing a job. The level of the benefits is set at the "gross minimum wage". Once these benefits expire, individuals are eligible for supplementary allowances equal to 40 percent of the minimum wage for up to 18 months. Mandatory participation in training and evidence of active job search are required to continue to receive these benefits. During the time of the survey, less than 5 percent of the households received these benefits.

Numerous other public pensions and benefits are also provided to Romania's households, and we lump them together for the remainder of this analysis. They include a range of types of social assistance, such as canteens, benefits for wives of conscripts, birth indemnities, payments to orphans and the handicapped, as well as payments to wives of former political prisoners. Overall, 80 percent of the households in Romania receive some form of transfer payment. As a share of total income, these payments represent 17.2 percent on average.

\section{METHODOLOGY}

\section{Testing for Progressivity of Public Transfers}

A general method for comparing the incidence of public transfers is to test for welfare dominance (Atkinson, 1970; Fellman, 1977; Kakwani, 1977. See Yitzhaki and Slemrod, 1991, for a clear application). The idea is to construct "concentration curves", diagrams which are similar to Lorenz curves in that they plot households from the poorest to the wealthiest on the horizontal axis against the cumulative proportion of transfers received for all households from the poorest up to household n. For any social welfare function that favors an equitable distribution of income, changing the structure of transfers by slightly increasing 
one transfer, $x$, and reducing those on another, $y$, by just enough to keep total expenditures constant will improve social welfare when $x$ 's concentration curve is everywhere above $y$ 's. ${ }^{4}$ The intuition is straightforward. If poorer households tend to receive were of a particular type of transfer payment, say unemployment compensation, and less of another, say social security payments, then reducing expenditures on the latter to pay for more of the former will improve the distribution of welfare. This is often called "welfare dominance" because of the analogy with the concept of second order stochastic dominance in the finance literature.

In addition to comparing the concentration curves for different public transfers, we also compare each concentration curve to two benchmarks: the Lorenz curve for expenditures and the 45-degree line. Analogous to the tax literature, we can say that an expenditure is progressive if it benefits poorer households more than wealthy ones, relative to their income, and regressive if it does not. At the same time, public transfer payments are often held to a higher standard than taxes in their being considered well-targeted to the poor only if the benefits go disproportionately to the poor in absolute terms, not merely relative to income. We will call such transfers "per capita progressive" and note that they have a concentration curve that is above the 45-degree line (concave rather than convex). We will call transfers whose concentration curve is above the Lorenz curve but below the 45-degree line simply "progressive" and those below the Lorenz curve are "regressive", analogous to the standard tax literature.

Since the concentration curves are constructed from sample data, comparisons between them are, or should be, statistical. ${ }^{5}$ Beach and Davidson (1983) first derived distribution-free standard errors for comparison of independent Lorenz curves. However, while such standard errors are adequate for comparing distributions across independent populations, a problem arises in the case of testing dominance of transfer payments that may be correlated with income, as well as each other. Since the transfers we study are either means tested or linked to employment status, it is implausible to assume that their distribution is independent of income or each other. In a recent paper, Davidson and Duclos (1997) derive distribution-free standard errors for the difference between two concentration curves which may be dependent. We use the Davidson and Duclos' estimator to establish a confidence interval around the estimated concentration curves and then test for significant differences between them.

In addition to accounting for the possible dependence between concentration curves, our tests differ from most of the literature in the way that we use the covariance matrix for the ordinate estimates. Typically, researchers who apply statistical tests use $t$-tests for the difference between the ordinates of two concentration curves at several abscissa (usually 0.1 to 0.9 ). Then they reject the null hypothesis of non-dominance when one of the ordinates differs statistically in the

\footnotetext{
${ }^{4}$ Technically, the argument also requires that the efficiency consequences of the expenditure/tax change be at least neutral, i.e. that the efficiency of the allocation of resources not worsen with the change. This condition is more difficult to identify in practice, but we will assume that it is satisfied in our discussion.

${ }^{5}$ It is not unusual that findings regarding dominance lack statistical tests of differences in concentration curves. See, for example, Jenkins and Lambert (1993).
} 
direction of dominance, as long as none of the other pairs indicates a statistically significant result in the opposite direction. ${ }^{6}$ Howes (1996a) shows that we can only be sure that the probability of type I error is no more than the significance level used if we reject the null hypothesis in favor of dominance only when the ordinates of the two curves are significantly different at every point tested and, obviously, that the difference be of the same sign. This decision rule is clearly less likely than the more common one to reject the null in favor of dominance. In practice, we find that it leads us to accept the null quite often, leaving us with little to conclude about the relative progressivity of transfers. However, bounding the size of the test at the risk of low power is consistent with standard econometric practice, and we follow it here. Of course, as indicated above, failure to reject the null leaves us with an indeterminate result, unless we can establish that the two concentration curves cross, something shown by two significant differences in ordinates of opposite signs.

In theory, we can establish welfare dominance only if one concentration curve is above another at every point. In practice, $t$-statistics for the difference of ordinates almost always go to zero as we approach the extremes of the distribution ( 0 and 1$)$, and statistical testing of very small quantiles is also limited by the sample size. As a result, we are limited to what Howes (1996) refers to as "restricted" dominance. This involves excluding the extreme tails so that we reject the null even if the curves cross or are not significantly different in that range. Choosing how restrictive to be is difficult and arbitrary. Many papers use ordinates at the deciles ( 0.1 to 0.9$)$, which ignores fairly large sections of the income distribution and thus weakens the economic significance of any conclusion that one transfer dominates another. On the other hand, choosing very small quantiles reduces the power of the test as standard errors become based on very few observations for lower quantiles. Based on our sample size of 16,000 households, we will extend the range of values over which we test dominance to the first percentile of the income distribution at the bottom and the ninety-ninth percentile at the top, so that each quantile has about 160 households, a number that is usually considered sufficient for asymptotic results. ${ }^{7}$ Practically, this decision has important consequences: examination of the difference in ordinates in these extreme ranges (especially in the top and bottom 3 percent of the income distribution) often reverses a decision based on the deciles alone. In sum, our decision rule is this: over a restricted range, we reject the null in favor of dominance if all the $t$ statistics are greater than the critical value and of the same sign; or, we reject the null in favor of crossing if there are at least two significant $t$-statistics with opposite signs.

This strategy of comparing the concentration of two different transfers implicitly assumes that the appropriate measure of progressivity is the so-called tax redistribution (TR) measure (Pfähler, 1987), which compares concentration

\footnotetext{
${ }^{6}$ See, for example, the recent paper by Gouveia and Tavares (1995).

${ }^{7}$ We do not consider all the percentiles, since the covariance estimator becomes increasingly difficult to calculate with a large number of ordinates. Instead, because it is rare for the $t$-statistics to change dramatically in the center of the distribution, we use the abscissa 0.01 to $0.09,0.1$ to 0.9 , and 0.91 to 0.99 .
} 
curves ranked by the existing income distribution. This measure does not, however, account for the importance of the transfer in overall incomes. That is, transfers could be highly concentrated among poor households, but involve a trivial amount of money. Another way to examine the incidence of a transfer, known as the income redistribution (IR) approach, is to compare concentration curves of income before and after the transfer. Lambert (1993) discusses the differences between the measures. We present TR results here, mostly because we are interested in the equity implications of marginal budgetary reallocations from one transfer to another. In addition, the associated concentration curves are more visually distinct. For the same reason, we employ an income measure inclusive of transfer receipts to rank households.

When the dominance tests fail to reject the null, or indicate crossing, we are left with inconclusive results regarding the relative progressivity of different types of public transfers. In these cases, we can resort to some cardinal measure to draw conclusions about welfare evaluation and incidence. ${ }^{8}$ The most common is the Gini coefficient, though any of the several options for inequality indices are also plausible. In this paper, we report a generalized or extended Gini based on Yitzhaki (1983) which provides a middle ground between the normative generality (and consequent indeterminacy) of the welfare dominance approach and the precision (and lack of normative generality) of a cardinal measure of social welfare. ${ }^{9}$

The extended Gini coefficient has a clear relation to the Lorenz/concentration curves used in the dominance analysis: it is the weighted area between the 45-degree line and the Lorenz/concentration curve. Giving more weight to the area at the lower end of the distribution gives a clearer notion of how more progressive social welfare functions would rank distributions. The coefficient is defined as:

$$
G(v)=-v * \frac{\operatorname{Cov}\left\{y,[1-F(y)]^{(v-1)}\right\}}{\bar{y}}, \quad v>1
$$

where $y$ is the welfare variable (income per capita); $F(y)$ is its cumulative density function; $\bar{y}$ is mean welfare; and $v$ is a parameter that affects the weighting of each point on the Lorenz curve. $G(2)$ yields the traditional Gini coefficient, while values of $v$ greater than 2 yield measures that give even greater weight to poorer households. To measure the concentration of a variable other than the welfare measure, we can calculate extended Gini concentration ratios by substituting the value of the other variable for $y$ in the extended Gini formula except that the cumulative density, $F(y)$, remains a function of the welfare variable $y$. For simplicity we will refer to extended Gini coefficients and extended Gini concentration

\footnotetext{
${ }^{8}$ Recall that if one distribution is welfare dominant over another, then the first will be preferred to the second under any social welfare function that favors progressivity.

${ }^{9} \mathrm{~A}$ referee has pointed out that there is no social welfare function with the usual properties of being individualistic and differentiable (as well as increasing) that is consistent with the Gini index. While the Gini coefficient can be consistent with non-individualistic social welfare functions, in particular functions that depend on a person's income relative to other's (e.g., Runciman, 1966), the generalized Ginis do not represent a subset of the class of utility functions that the inequality dominance literature usually considers. We find them useful nevertheless, because of their obvious statical relationship to the Lorenz curve, and because they provide a simple way to calculate the orderpreserving TR comparisons that we use in this paper.
} 
ratios as "extended Ginis". By calculating the extended Gini coefficients for increasing values of $v$, we can gain a sense of how a more progressive (yet still cardinal) social welfare function ranks the value of a given public service. To draw conclusions similar to the dominance tests, we calculate Ginis for $v$ values from 1.01 to 4 in steps of 0.5 for income and for all the transfers. ${ }^{10}$ If all 7 pairs of extended Ginis (from $v=1.01$ to 4 ) are significantly less for one of the transfers, we conclude that it "dominates" the other. Our use of this term clearly does not have the same rigorous foundation in welfare analysis as the ordinal measure. We choose it only because the implied policy conclusion is similar, even if it is based on cardinal measures.

\section{Adjusting Household Incomes for Household Size and Composition}

Most empirical work on the incidence of taxes and transfers uses household income per capita to measure household welfare. ${ }^{11}$ However, much recent poverty literature argues that this choice is arbitrary and that any other choice for adjusting household incomes for differences in size and composition is more a reflection of a researcher's value judgment rather than an empirically testable empirical scale (Deaton and Muellbauer, 1980, 1986; Lanjouw and Ravallion, 1995; Browning, 1992; Blundell and Lewbel, 1991; Coulter, Cowell, and Jenkins, 1992). Furthermore, previous empirical research has shown the importance of the judgments made regarding equivalence on measures of inequality, particularly the range of cardinal measures, but also ordinal measures represented by the Lorenz curve. $^{12}$ In this paper, we add to those findings by testing the sensitivity of the dominance tests, and the extended Ginis, to different assumptions about how household size and composition affect the money metric of their welfare. We consider four equivalence scales, three of which rely on a single parameter characterization of the money metric of equivalent incomes, and the other varying along two dimensions: the number of persons in the family and the share of those that are children. Specifically, we define equivalent incomes as:

$$
Y_{i}^{*}=Y_{i} /\left(A_{i}+c K_{i}\right)^{\theta},
$$

where $\theta$ represents the elasticity with respect to household size (i.e., the size or equivalence elasticity), $Y_{i}$ is household income, and $A_{i}$ and $K_{i}$ is the number of adults and children in the household, respectively. When $c=\theta=1$, we have simple per capita scaling. We also use $c=1$ with $\theta=0.5$, and we parameterize equivalent persons following a recent recommendation that $c$ be set to 0.7 , implying that children's resource costs are 70 percent as much as adults, and then, raising that

\footnotetext{
${ }^{10}$ Duyclos (forthcoming) uses leaky bucket experiments to argue that 4 is a reasonable upper bound on the $v$ parameter.

${ }^{11}$ Throughout the paper, we make interpersonal comparisons based on money income of the households. In practice, the distribution of money income represents a welfarist approach to social evaluation, a standard practice that arguably has ome important limitations. For a discussion of the limits of utility measure of welfare, see van der Walle and Nead (1995). In addition, we rely on the standard assumption that each person in the household unit has equal utility.

${ }^{12}$ Buhmann et al. (1988) show that the degree of inequality, and the ranking of cardinal measures of inequality are not robust to the choice of size elasticities. Cutler and Katz (1992) show that while inequality is sensitive to the choice of equivalence scales, inequality trends seem to be robust to the range of "reasonable" adjustments made for household size and composition.
} 
value to $\theta=0.7(N R C, 1995)$. While none of these scales has a compelling theoretical or empirical justification, they cover the wide range of assumptions that have been made in empirical work on income distribution and thus yield a test of robustness over a typical range of equivalence scales.

\section{RESULTS}

\section{Test of Welfare Dominance}

Figure 1 presents the concentration curves of the various public transfers in Romania using a per capita measure of expenditure, with no account made for the

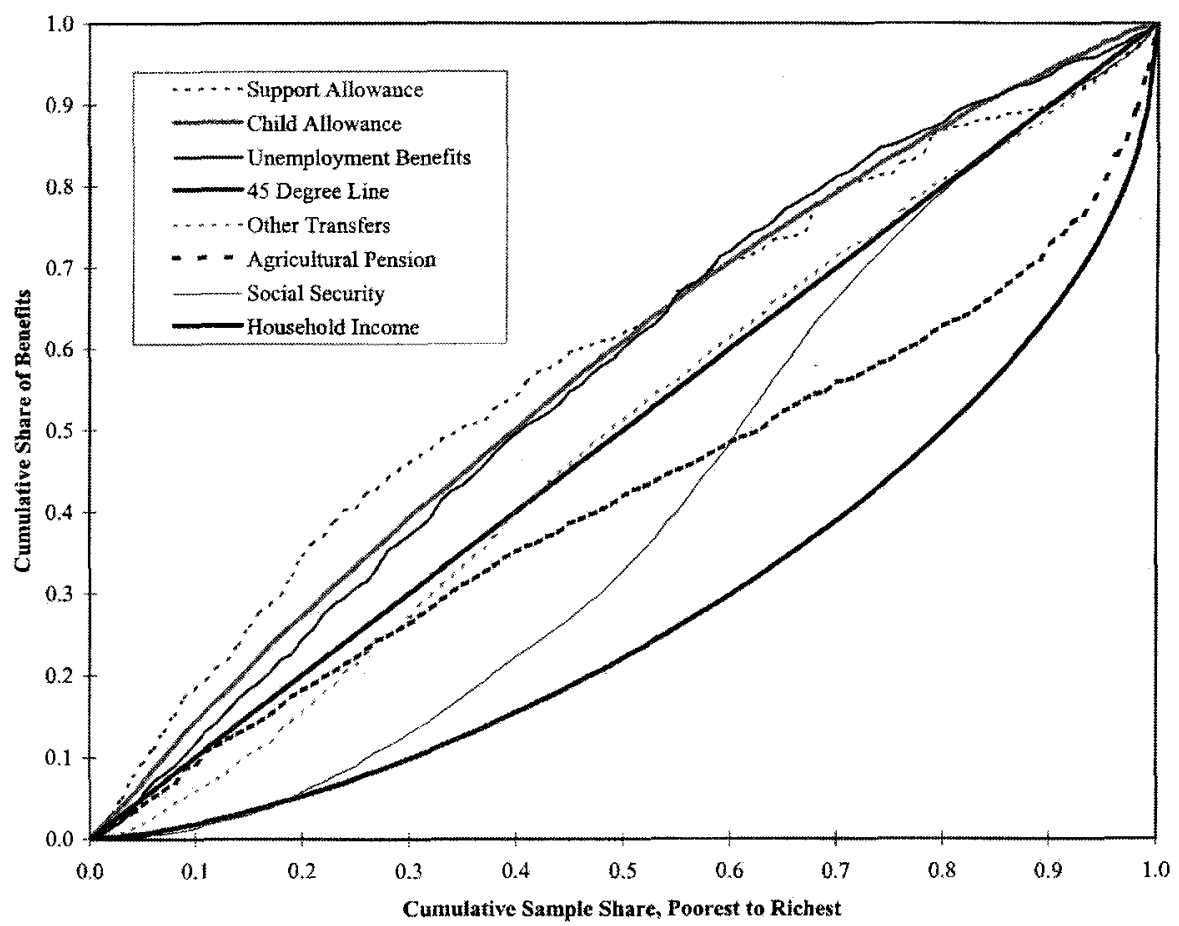

Figure 1. Lorenz and Concentration Curves for Transfers in Romania

age/gender differences in the composition of the household. Casual observation indicates that all the transfers, with the exception of social security, are everywhere above the per capita income Lorenz curve. For social security, it is only in the lower 20 percent of households that the curve falls below the income curve. Only child allowances appear to be per capita progressive- that is, everywhere above the 45-degree line-although both unemployment benefits and supplementary allowances are above the 45-degree line for a wide range of the households in the population. Among the transfers themselves, an evaluation of their relative progressivity is less clear. Most of the concentration curves appear to cross, often away from the extreme deciles. Social security payments are especially concentrated among the fifth to eighth deciles, while the other main pension scheme (for 
agriculture) is much more concentrated in the lower four deciles and, curiously, the top decile. Unemployment benefits go mostly to the second through sixth deciles of the income distribution, while supplementary allowances for the longterm unemployed is more concentrated in the first through fourth deciles, though they appear also to go disproportionately to the wealthiest decile.

While the figure is informative, it is still necessary to test statistically the null hypothesis of non-dominance. Table 2 summarizes the results of the statistical evaluation of dominance based on the per capita measure of equivalent income. ${ }^{13}$ All of the transfer payments except social security and other pensions and benefits are progressive, i.e. their concentration curves dominate the Lorenz curve. For other pensions and benefits, only one ordinate pair (the first, 0.01) is insignificantly different, so these transfers are very close to being progressive as well. For social security, on the other hand, there is a clear crossing well away from the origin, at about 0.17 .

Even though most of the transfers are progressive, only one, child allowances, is per capita progressive, while all of the others either cross the 45-degree line or are statistically indistinguishable from it. Thus, while these transfers are progressive, they are perhaps not as well-targeted as one might hope for. Nevertheless, their overall impact is quite substantial. An IR comparison between income with and without all transfer payments shows that the former is significantly more equitable than the latter, with the Gini coefficient declining from 0.50 to 0.44 . This result reflects both the progressivity of the transfers and their relatively large share of overall household income.

Comparisons among the various transfers are much less conclusive. Of the 15 possible pairwise comparisons, only two reject the null in favor of dominance: child allowances dominate both agricultural and social security pensions. Four others show crossing, while nine do not reject the null. With so few dominance results, these data do not provide much guidance for budgetary reallocation of transfer payments from one type to another. Further, there are obvious reasons to expect that the two dominance results will not be robust to choice of equivalence units, as the next section shows.

\section{Sensitivity to Household Scaling}

Table 3 summarizes the statistical tests for dominance under two alternative household equivalence scales, one with $c=1$ and $\theta=0.5$ and one with $c=0.7$ and $\theta=0.7$ (the NCS scale). Child allowances no longer dominate pensions under either scaling, which is consistent with the lower weight on both children and household size in the NCS scale. In fact, there are no cases of dominance when comparing between different transfer payments. The progressivity results, however, are robust to the variation in equivalency, with only one change: unemployment benefits no longer dominate the Lorenz curve, though for both scales, this result is due to one insignificant $t$-statistic at the first ordinate $(0.01)$. We cannot reject the null for other pensions and benefits for the same reason, as in the per capita case. Finally, child allowances are no longer per capita progressive under either alternative scale.

$$
{ }^{13} c=1 ; \theta=1 \text {. }
$$


TABLE 1

Share of Households Receiving Transfers and Benefits and Mean Value Per Household

\begin{tabular}{|c|c|c|c|c|c|c|}
\hline & $\begin{array}{l}\text { Social } \\
\text { Security }\end{array}$ & $\begin{array}{l}\text { Agricultural } \\
\text { Pension }\end{array}$ & $\begin{array}{l}\text { Unemployment } \\
\text { Benefits }\end{array}$ & $\begin{array}{l}\text { Supplementary } \\
\text { Allowances }\end{array}$ & $\begin{array}{c}\text { Child } \\
\text { Allowances }\end{array}$ & $\begin{array}{l}\text { Other Pensions } \\
\text { and Benefits }\end{array}$ \\
\hline Percent of households receiving & 27.2 & 13.1 & 6.8 & 4.2 & 41.9 & 19.9 \\
\hline $\begin{array}{l}\text { Average value as percent of recipient } \\
\text { household income }\end{array}$ & 15.4 & 1.9 & 1.6 & 0.8 & 2.2 & 6.5 \\
\hline
\end{tabular}

Note: We calculate the weighted averages for all houscholds in the sample, whether or not they receive any particular transfer.

TABLE 2

Dominance Test Results, $\theta=1$

\begin{tabular}{|c|c|c|c|c|c|c|c|c|}
\hline & Income & $\begin{array}{l}\text { Social } \\
\text { Security }\end{array}$ & $\begin{array}{l}\text { Agricultural } \\
\text { Pensions }\end{array}$ & $\begin{array}{c}\text { Other } \\
\text { Benefits }\end{array}$ & $\begin{array}{l}45 \text { Degree } \\
\text { Line }\end{array}$ & $\begin{array}{c}\text { Unemployment } \\
\text { Benefits }\end{array}$ & $\begin{array}{c}\text { Child } \\
\text { Allowances }\end{array}$ & $\begin{array}{c}\text { Supplementary } \\
\text { Allowances }\end{array}$ \\
\hline \multicolumn{9}{|l|}{ Income } \\
\hline Social Security & $\mathrm{X}$ & & & & & & & \\
\hline Agricultural Pensions & $\mathrm{D}$ & $\mathrm{X}$ & & & & & & \\
\hline Other Benefits & 0 & 0 & $\mathrm{X}$ & & & & & \\
\hline 45 Degree Line & $\mathrm{D}$ & 0 & 0 & 0 & & & & \\
\hline Unemployment & $\mathrm{D}$ & 0 & 0 & 0 & $\mathrm{X}$ & & & \\
\hline Child Allowances & $\mathrm{D}$ & D & $\mathrm{D}$ & 0 & D & 0 & & \\
\hline
\end{tabular}

Note: In this and all the following tables, $\mathrm{D}=$ row dominates column, $\mathrm{X}=$ crossing, 0 accepts the null of no dominance and no crossing. 
TABLE 3

Dominance Results as in Table 2, with Alternative Equivalence Scales

\begin{tabular}{|c|c|c|c|c|c|c|c|c|c|c|c|c|c|c|c|c|c|c|c|c|c|}
\hline & \multicolumn{3}{|c|}{ Income } & \multicolumn{3}{|c|}{$\begin{array}{c}\text { Social } \\
\text { Security }\end{array}$} & \multicolumn{3}{|c|}{$\begin{array}{c}\text { Agricultural } \\
\text { Pensions }\end{array}$} & \multicolumn{3}{|c|}{$\begin{array}{c}\text { Other } \\
\text { Pensions and } \\
\text { Benefits }\end{array}$} & \multicolumn{3}{|c|}{$\begin{array}{l}45 \text { Degree } \\
\text { Line }\end{array}$} & \multicolumn{3}{|c|}{$\begin{array}{c}\text { Unemployment } \\
\text { Benefits }\end{array}$} & \multicolumn{3}{|c|}{$\begin{array}{c}\text { Child } \\
\text { Allowances }\end{array}$} \\
\hline & (1) & (2) & (3) & (1) & $(2)$ & (3) & (1) & (2) & (3) & (1) & (2) & (3) & (1) & $(2)$ & (3) & (1) & (2) & (3) & (1) & (2) & (3) \\
\hline \multicolumn{22}{|l|}{ Income } \\
\hline Social Security & $\mathrm{X}$ & $\mathrm{X}$ & $\mathrm{X}$ & & & & & & & & & & & & & & & & & & \\
\hline Agricultural Pensions & $\mathrm{D}$ & $\mathrm{D}$ & $\mathrm{D}$ & $\mathrm{X}$ & $\mathrm{X}$ & $\mathrm{X}$ & & & & & & & & & & & & & & & \\
\hline Other Benefits & 0 & 0 & 0 & 0 & 0 & 0 & $\mathrm{X}$ & $\mathrm{X}$ & $\mathrm{X}$ & & & & & & & & & & & & \\
\hline 45 Degree Line & $\mathrm{D}$ & $\mathrm{D}$ & $\mathrm{D}$ & 0 & $\mathrm{X}$ & $\mathrm{X}$ & 0 & $\mathrm{X}$ & $\mathrm{X}$ & 0 & $\mathrm{X}$ & $\mathrm{X}$ & & & & & & & & & \\
\hline Unemployment Benefits & $\mathrm{D}$ & 0 & 0 & 0 & 0 & 0 & 0 & $\mathrm{X}$ & $\mathrm{X}$ & 0 & 0 & 0 & $\mathrm{X}$ & $\mathrm{X}$ & $\mathrm{X}$ & & & & & & \\
\hline Child Allowances & $\mathrm{D}$ & $\mathrm{D}$ & $\mathrm{D}$ & $\mathrm{D}$ & 0 & 0 & $\mathrm{D}$ & $\mathrm{X}$ & $\mathrm{X}$ & 0 & 0 & 0 & $\mathrm{D}$ & 0 & 0 & 0 & $\mathrm{X}$ & 0 & & & \\
\hline Supplementary Allowances & D & $\mathrm{D}$ & $\mathrm{D}$ & 0 & 0 & 0 & 0 & 0 & 0 & 0 & 0 & 0 & 0 & 0 & 0 & $X$ & $X$ & $\mathrm{X}$ & $\mathrm{X}$ & $\mathrm{X}$ & $\mathrm{X}$ \\
\hline
\end{tabular}

Note: (1) is per capita scaling, (2) is the NCS scale, and (3) is a scale with household size raised to 0.5 . 


\section{Sensitivity to the Decision Rule}

Table 4 summarizes dominance test results for three different decision rules: (1) the one adopted above; (2) a similar rule that considers only nine evenlyspaced ordinates from 0.1 to 0.9 ; and (3) a rule that uses only 9 ordinates and rejects the null in favor of dominance if only one $t$-statistic is significant and no other is significant in the opposite direction. Both of these alternative rules are common in the applied literature. As we discussed earlier, Howes' (1996) work suggests that rule (3) is particularly unattractive since its size cannot be bounded. Nevertheless, it is common, so we include it here for comparison's sake. Comparison with rule (2) gives a sense of how important the restriction in restricted dominance is.

Using a more restricted dominance test (rule (2) rather than rule (1)) for the per capita results leads to five more rejections of the null in favor of dominance and one less rejection in favor of crossing, out of the 28 possible comparisons between the concentration curves, the Lorenz curve, and the 45-degree line. For the alternative equivalence scales, the improvement is even better, increasing by seven for the NCS scale and six for the scale with $\theta=0.5$. At the same time, the number of rejections in favor of crossing declines substantially for these scales, by six and four, respectively. Thus, there is a considerable amount of action near the extremes of the distribution. Ignoring those ranges can yield more conclusive dominance results, but there is an important cost in that the "dominance" is restricted to social welfare functions that are indifferent to the relative welfare of the first and last deciles of the sample, a limitation that clearly reduces its generality.

The traditional decision rule number (3) produces even more conclusive results, with a rejection (either for dominance or for crossing) in virtually every pairwise comparison. This is perhaps not too surprising since the size of the test is not bounded, and it serves to highlight Howes' point that rejections under this rule conclude far too easily that there is dominance.

\section{Cardinal Measures}

The attractiveness of the dominance tests is that they are very general, providing a welfare ordering for any anonymous social welfare function that favors equality. Their weakness is that they are often inconclusive and may suffer from low power. One way to increase the power is to restrict the range of the test. As the last section shows, this can yield significantly more rejections of the null in favor of dominance, at a cost of generality. Another alternative is to choose a specific cardinal social welfare function, also at a cost of generality. We explore that option in this section, using extended Gini coefficients. In an attempt to increase the generality somewhat, we use a wide parameter range, with $v$ varying from 1.01 to 10 . Table 5 shows the extended Gini coefficients for income and all the transfers, as well as the $t$-statistics for the differences between the extended Ginis for each of the types of transfers and the corresponding Gini for per capita income.

Table 6 summarizes the results by concluding that one transfer "dominates" another if its Gini coefficients are significantly lower than another's for all values 
TABLE 4

Dominance Results as in Table 2, with Alternative Decision Rules

\begin{tabular}{|c|c|c|c|c|c|c|c|c|c|c|c|c|c|c|c|c|c|c|c|c|c|}
\hline & \multicolumn{3}{|c|}{ Income } & \multicolumn{3}{|c|}{$\begin{array}{c}\text { Social } \\
\text { Security }\end{array}$} & \multicolumn{3}{|c|}{$\begin{array}{c}\text { Agricultural } \\
\text { Pensions }\end{array}$} & \multicolumn{3}{|c|}{$\begin{array}{c}\text { Other } \\
\text { Pensions and } \\
\text { Benefits }\end{array}$} & \multicolumn{3}{|c|}{$\begin{array}{l}45 \text { Degree } \\
\text { Line }\end{array}$} & \multicolumn{3}{|c|}{$\begin{array}{c}\text { Unemployment } \\
\text { Benefits }\end{array}$} & \multicolumn{3}{|c|}{$\begin{array}{c}\text { Child } \\
\text { Allowances }\end{array}$} \\
\hline & (1) & $(2)$ & (3) & (1) & (2) & (3) & (1) & (2) & (3) & (1) & (2) & (3) & (1) & (2) & (3) & (1) & $(2)$ & (3) & (1) & $(2)$ & (3) \\
\hline \multicolumn{22}{|l|}{ Income } \\
\hline Social Security & $\mathrm{X}$ & $\mathrm{X}$ & $\mathrm{X}$ & & & & & & & & & & & & & & & & & & \\
\hline Agricultural Pensions & $\mathrm{D}$ & $\mathrm{D}$ & D & $\mathrm{X}$ & $\mathrm{X}$ & $\mathrm{X}$ & & & & & & & & & & & & & & & \\
\hline Other Pensions and Benefits & 0 & $\mathrm{D}$ & D & 0 & 0 & $\mathrm{D}$ & $\mathrm{X}$ & $\mathrm{X}$ & $\mathrm{X}$ & & & & & & & & & & & & \\
\hline 45 Degree Line & $\mathrm{D}$ & $\mathrm{D}$ & $\mathrm{D}$ & 0 & 0 & $\mathrm{D}$ & 0 & 0 & $\mathrm{D}$ & 0 & 0 & $\mathrm{D}$ & & & & & & & & & \\
\hline Unemployment Benefits & $\mathrm{D}$ & $\mathrm{D}$ & $\mathrm{D}$ & 0 & $\mathrm{D}$ & $\mathrm{D}$ & 0 & 0 & $\mathrm{D}$ & 0 & $\mathrm{D}$ & $\mathrm{D}$ & $\mathrm{X}$ & 0 & $\mathrm{D}$ & & & & & & \\
\hline Child Allowances & $\mathrm{D}$ & D & $\mathrm{D}$ & $\mathrm{D}$ & $\mathrm{D}$ & $\mathrm{D}$ & $\mathrm{D}$ & $\mathrm{D}$ & $\mathrm{D}$ & 0 & $\mathrm{D}$ & $\mathrm{D}$ & $\mathrm{D}$ & $\mathrm{D}$ & $\mathrm{D}$ & 0 & 0 & $\mathrm{D}$ & & & \\
\hline Supplementary Allowances & $\mathrm{D}$ & $\mathrm{D}$ & D & 0 & 0 & 0 & 0 & $\mathrm{D}$ & $\mathrm{D}$ & 0 & 0 & $D$ & 0 & 0 & $\mathrm{D}$ & $X$ & $X$ & $X$ & $\mathrm{X}$ & $X$ & $X$ \\
\hline
\end{tabular}

Notes: (1) Tests at $0.01-0.09,0.1-0.9$, and $0.91-0.99$, and uses Howes' rejection criterion: (2) tests at $0.1-0.9$ and uses Howes' rejection criterion; (3) tests at

0.1-0.9 and uses the traditional rejection criterion. Similar tables for alternative equivalence scales are available from the authors. 
TABLE 5

Extended Gini Coefficients and $t$-Statistics for Difference in Ginis

\begin{tabular}{|c|c|c|c|c|c|c|c|}
\hline$v$ & $\begin{array}{l}\text { Per Capita } \\
\text { Income }\end{array}$ & $\begin{array}{c}\text { Agricultural } \\
\text { Pensions }\end{array}$ & $\begin{array}{c}\text { Child } \\
\text { Allowances }\end{array}$ & $\begin{array}{l}\text { Other } \\
\text { Benefits }\end{array}$ & $\begin{array}{c}\text { Social } \\
\text { Security }\end{array}$ & $\begin{array}{c}\text { Supplementary } \\
\text { Allowances }\end{array}$ & $\begin{array}{l}\text { Unemployment } \\
\text { Benefits }\end{array}$ \\
\hline \multicolumn{8}{|c|}{ Extended Gini Coefficients } \\
\hline 1.01 & 0.0121 & 0.0058 & -0.0024 & 0.0003 & 0.0020 & -0.0019 & -0.0021 \\
\hline 1.50 & 0.3166 & 0.1462 & -0.0909 & 0.0093 & 0.0933 & -0.0936 & -0.0843 \\
\hline 2.00 & 0.4399 & 0.1713 & -0.1490 & 0.0192 & 0.1853 & -0.1805 & -0.1351 \\
\hline 2.50 & 0.5099 & 0.1691 & -0.1902 & 0.0341 & 0.2699 & -0.2548 & -0.1652 \\
\hline 3.00 & 0.5572 & 0.1608 & -0.2212 & 0.0528 & 0.3439 & -0.3178 & -0.1829 \\
\hline 3.50 & 0.5923 & 0.1521 & -0.2454 & 0.0735 & 0.4071 & -0.3716 & -0.1930 \\
\hline 4.00 & 0.6198 & 0.1444 & -0.2650 & 0.0951 & 0.4607 & -0.4181 & -0.1984 \\
\hline \multicolumn{8}{|c|}{$t$-Statistics for Difference with Per Capita Income } \\
\hline 1.01 & - & -9.79 & -54.49 & -24.82 & -35.39 & -18.22 & -35.70 \\
\hline 1.50 & - & -11.57 & -69.58 & -28.31 & -34.82 & -20.01 & -37.98 \\
\hline 2.00 & - & -12.97 & -79.77 & -29.08 & -30.19 & -20.38 & -35.85 \\
\hline 2.50 & - & -13.72 & -83.60 & -28.31 & -24.93 & -19.78 & -32.77 \\
\hline 3.00 & - & -14.04 & -83.76 & -27.13 & -20.58 & -19.04 & -30.14 \\
\hline 3.50 & - & -14.11 & -82.42 & -25.95 & -17.23 & -18.42 & -28.06 \\
\hline 4.00 & - & -14.07 & -80.55 & -24.89 & -14.65 & -17.95 & -26.42 \\
\hline
\end{tabular}


TABLE 6

Dominance Results Based on Extended Ginis, with Alternative Equivalnce Scales

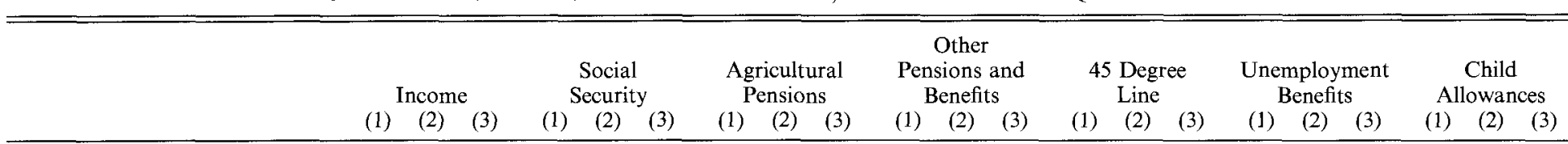

Income

Social Security

Agricultural Pensions

Other Pensions and Benefits

45 Degree Line

$\mathrm{D} \quad \mathrm{D} \quad \mathrm{D}$

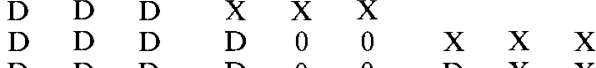

Unemployment Benefits

Child Allowances

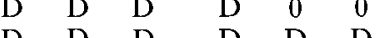

Supplementary Allowances

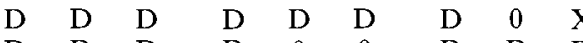

Note: (1) is per capita scaling, (2) is the NCS scale, and (3) is a scale with household size raised to 0.5. 
of $v$ considered. Similarly, there is a crossing if the $t$-statistics are significant but with different signs over the range of $v$. For per capita scaling, the results are much more conclusive than the ordinal results, with 23 of 28 pairwise comparison rejecting the null in favor of dominance, including many comparisons between different transfer payments. Given the wide range of $v$ values that we used, this would appear to be an attractive alternative to the dominance techniques. Unfortunately, it is not very robust to changes in the equivalency scale. For the NCS scale, the number of dominance results falls to 14 , and for $\theta=0.5$, it is only 11 , with only 3 for comparisons between transfer payments. Thus, at least for this sample, even going to a cardinal welfare function does not provide policy recommendations that are robust to equivalency scale.

\section{DISCUSSION}

Our original goals for this research were to determine how progressive existing transfer payments are in Romania and, in light of the need to target transfers well in an era of declining public resources, to indicate which transfers are most beneficial to the poor. Our results on the first question are reasonably conclusive and robust to variations in household scaling: all of the transfers except social security payments and other pensions and benefits are progressive in the sense that their concentration curves dominate the Lorenz curve, and the latter misses a rejection by only one ordinate, at the first percentile. At the same time, none of the transfers consistently dominates the 45-degree line, though many cross it or are statistically indistinguishable from it, and child allowances do dominate when we scale households by simple per capita income. Thus, in broad terms, we can conclude that transfer payments are progressive, but not per capita progressive, in Romania. The overall impact on the distribution of income is substantial: income inclusive of transfers dominates pre-transfer income, and the Gini coefficient drops from 0.50 to 0.44 . Likewise, we find that regardless of the choice of equivalence scale, income without transfers are statistically dominated by those with transfers. Thus, our results are consistent with the popular notion that transfer payments in general provide an important cushion for poorer households in Romania.

Our results on the second question are far less conclusive. We find only two dominance orderings (child allowances over both agricultural and social security pensions) among the 15 possibilities when scaling by household size, and none for either the NCS scaling or a theta value of 0.5 . Thus, these results offer little guidance for policymakers interested in better targeting of transfer payments. In part, this is due to our use of more careful methods than are common in the literature. If we restrict the range of comparisons to $0.1-0.9$, the number of dominance results rises from 2 to 6 out of 15 for per capita scaling. If we change the decision rule to reject the null whenever there is at least one significantly different ordinate pair and no other significant differences of the opposite sign, then we get 10 rejections in favor of dominance.

It would be wrong, however, to attribute the lack of dominance orderings entirely to our choice of methods. First, statistical tests reveal that many of the 
concentration curves actually cross, especially when using the alternative equivalence scales. In these cases, lack of a dominance result is not a problem of low power, but a reflection of the data. This is supported by simple examination of the concentration curves, which shows that they do in fact cross or come close to each other in many cases, even ignoring the extremes of the curves. Thus, it would be odd to find many cases of dominance here. Transfers in Romania really are such that it is difficult to make general statements about which are more progressive.

Second, it should be difficult to find a clear dominance result in most cases. The concept of dominance is a very strong one, implying preference under any anonymous and equality-favoring welfare function. This includes even Rawlsian functions which put positive weight only the poorest person's income. ${ }^{14}$ It would be surprising to find very many cases of taxes or transfers that satisfy this criterion. Thus we think that our decision rule is correct, and that it yields results consistent with what we should expect conceptually.

We also feel that our use of ordinate comparisons at the percentile level rather than the more common deciles is appropriate, at least for this data set. As Howes (1996b) points out, researchers must restrict their dominance comparisons away from 0 and 1 in practical applications to avoid allowing the poorest or richest household's behavior to have undue influence on the results. Yet a decile is a very large share of the sample to ignore. In our sample, for example, it comprises 1,600 households. Alternatively, a percentile includes 160 households, a number that we usually consider "large" enough for asymptotic results. So, while it may be frustrating to miss a rejection on the basis of one or two ordinates near the extremes, that would seem to be the appropriate decision. In sum, we think that our inability to find clear dominance orderings is based on appropriate methods and that it accurately reflects the reality of transfers in Romania.

In terms of policy, this means that we cannot offer clear guidelines to help policy makers decide how to reallocate their transfer budget so as to further reduce inequality. Any decision will have to be based on a more restricted set of welfare functions. We have explored one set here, those defined by extended Gini coefficients, with only mixed results. For the per capita scaling, this seems promising. Even for a wide range of parameter values, we find clear preference orderings for 10 of the 15 possible comparisons between transfers. However, as with other studies that have looked at the importance of household scaling, we find that this certainty is not robust to variations in the household equivalence scale. The number of rejections drops to 3 for $\theta=0.5$ and 4 for the NCS scale.

While the lack of a clear policy conclusion is discouraging, it would be premature to discard the dominance methods. To our knowledge, this is the first attempt to use them for a wide range of subsidies in an eastern European (or developing) country. Given that many of the concentration curves cross, and that most of the subsidies that we can examine are correlated with households size, these data do not lend themselves to clear distinctions between what is driven by

\footnotetext{
${ }^{14}$ Technically, this would be the poorest one percent of people in our case, since we restrict our ordinate comparisons to percentiles.
} 
methods and what is driven by the peculiarities of the Romania data. Further research with different data is surely in order.

\section{REFERENCES}

Atkinson, A. B., On the Measurement of Inequality, Journal of Economic Theory, 2, 244-63, 1970.

Beach, C. M. and R. Davidson, Distribution-free Statistical Inference with Lorenz Curves and Income Shares, Review of Economic Studies, 50, 723-35, 1983.

Bishop, J. A., J. P. Formby, and W. J. Smith, International Comparisons of Income Inequality: Tests for Lorenz Dominance Across Nine Countries, Economica, 58, 461-77, 1991.

Bishop, J. A., J. P. Formby, and P. D. Thistle, Convergence of the South and Non-South Income Distributions, American Economic Review, 82, 262-72, 1992.

Blundell, R. and A. Lewbel, The Information Content of Equivalence Scales, Journal of Econometrics, 50, 49-68, 1991.

Browning, M., Children and Household Economic Behavior, Journal of Economic Literature, 30 , $1434-75,1992$.

Buhmann, B., L. Rainwater, G. Schmaus, and T. M. Smeeding, Equivalence Scales, Well-being, Inequity, and Poverty: Sensitivity Estimates Across Ten Countries using the Luxembourg Income Study (LIS) Database, Review of Income and Wealth, 34, 115-42, 1988.

Coulter, F. A. E., F. Cowell, and S. Jenkins, Equivalence Scale Relativities and the Extent of Inequality and Poverty, The Economic Journal, 102, 1067-82, 1992.

- Differences in Needs and Assessment of Income Distributions. Bulletin of Economic Research, 44(2), 77-124, 1992 b.

Cutler, D. and L. Katz, Rising Inequality? Changes in Distribution of Income and Consumption in the 1980s. American Economic Review Papers and Proceedings, 82, 546-551, 1992.

Davidson, R. and J. Y. Duclos, Statistical Inference for the Measurement of the Incidence of Taxes and Transfers, Econometrica, 65, 1453-66, 1997.

Deaton, A and J. Muellbauer, Economics and Consumer Behavior. Cambridge University Press, Cambridge, 1980.

- On Measuring Child Costs: With Applications to Poor Countries. Journal of Political Economy, 94, 720-44, 1986.

Donaldson, D. and J. A. Weymark, A Single Parameter Generalization of the Gini Indices of Inequality, Journal of Economic Theory, 29, 353-8, 1980.

Duclos, Jean-Yves, Gini Indices and the Redistribution of Income, International Tax and Public Finance (forthcoming).

Fellman, J., The Effect of Transformations on Lorenz Curves, Econometrica, 44, 823-4, 1977.

Food and Agricultural Organization (FAO), Energy and Protein Requirements, Report of a Joint FAO/WHO Expert Group, FAO, Rome, 1972.

Gouveia, M. and J. Tavares, The Distribution of Household Income and Expenditure in Portugal: 1980 and 1990, Review of Income and Wealth, 41(1), 1-17, 1995.

Government of Romania, Romania Integrated Household Survey, Ministry of Labor and Social Protection/National Commission for Statistics, Bucharest, 1994.

Howes, S., A New Test for Inferring Dominance from Sample Data, Draft, 1996 .

, The Influence of Aggregation on the Ordering of Distributions, Economica, 63(250), May, 253-72, 1996b.

Jenkins, S. and P. Lambert, Ranking Income Distributions When Needs Differ, Review of Income and Wealth, 39(4), 337-356, 1993.

Kakwani, N., Applications of Lorenz Curves in Economic Analysis, Econometrica, 45, 719-28, 1977. , On a Class of Poverty Measures. Econometrica, 48, 437-46, 1980.

Lambert, P., The Distribution and Redistribution of Income: A Mathematical Analysis. 2nd edition. Manchester University Press, Manchester, 1993.

Lanjouw, P. and M. Ravallion, Poverty and Household Size. The Economic Journal, 105(433), 141534, 1995.

National Research Council, Measuring Poverty: A New Approach, Academic Press, Washington, DC, 1995.

Pfähler, W., Redistributive Effects of Tax Progressivity: Evaluating a General Class of Aggregate Measures, Public Finance/Finances Publiques, 42(3), 1-31, 1987.

Rao, R. C., Linear Statistical Inference and Its Applications, John Wiley and Sons Inc., New York, 1973.

Ravallion, M., D. Van de Walle, and M. Gautam, Testing a Social Safety Net, Journal of Public Economics, 57(1995), 175-99, 1995. 
Runciman, W. G., Relative Deprivation and Social Justice, Routledge and Kegan Paul, London, 1966. Silverman, B. W., Density Estimation for Statistics and Data Analysis, Chapman and Hall, London, 1986.

Van de Walle, D. and K. Nead, Public Spending and the Poor: Theory and Evidence, The John Hopkins University Press, Baltimore and London, 1995.

Van Praag, B. M. S., A. J. Hagenaars, and H. Van Weerden, Poverty in Europe, Review of Income and Wealth, 28(3), 345-59, 1982.

Yitzhaki, S., On an Extension of the Gini Inequality Index, International Economic Review, 24(3), $617-28,1983$.

Yitzhaki, S., and J. Slemrod, Welfare Dominance: An Application to Commodity Taxation. American Economic Review, 81(3), 480-96, 1991. 